\title{
Development of a Clinical Tool for Rating the Body Function Categories of the ICF Generic- 30/Rehabilitation Set in Japanese Rehabilitation Practice, and Examination of its Interrater Reliability
}

\section{Yuki Senju}

Department of Rehabilitation Medicine I, School of Medicine, Fujita Health University

Masahiko Mukaino ( $\nabla$ mmukaino@fujita-hu.ac.jp)

Department of Rehabilitation Medicine I, School of Medicine, Fujita Health University

\section{Birgit Prodinger}

Faculty of Applied Health and Social Sciences, Technical University of Applied Sciences, Rosenheim

\section{Melissa Selb}

Swiss Paraplegic Research

\section{Yuki Okouchi}

Department of Rehabilitation, Fujita Health University Hospital

\section{Kouji Mizutani}

Department of Rehabilitation, Fujita Health University Hospital

\section{Megumi Suzuki}

Faculty of Rehabilitation, School of Health Sciences, Fujita Health University

\section{Shin Yamada}

Department of Rehabilitation Medicine, Kyorin University School of Medicine

Shin-Ichi Izumi

Department of Physical Medicine and Rehabilitation, Tohoku University Graduate School of Medicine

\section{Shigeru Sonoda}

Department of Rehabilitation Medicine II, School of Medicine, Fujita Health University

\section{Yohei Otaka}

Department of Rehabilitation Medicine I, School of Medicine, Fujita Health University

\section{Eiichi Saitoh}

Department of Rehabilitation Medicine I, School of Medicine, Fujita Health University

\section{Gerold Stucki}

Swiss Paraplegic Research

\section{Research Article}


Keywords: Rehabilitation, International Classification of Functioning, Disability, Health, Interrater reliability, Clinical tool

Posted Date: November 25th, 2020

DOI: https://doi.org/10.21203/rs.3.rs-111560/v1

License: (c) (1) This work is licensed under a Creative Commons Attribution 4.0 International License. Read Full License 


\section{Abstract}

\section{Background}

The International Classification of Functioning, Disability, and Health (ICF) Generic-30 (Rehabilitation) Set is a tool for assessing the functioning of a clinical population in rehabilitation. The ICF Generic-30 consists of 9 ICF categories from the component "body functions" and 21 from the component "activities and participation". This study aimed to develop a rating reference guide for the 9 body function categories of the ICF Generic-30 Set using a predefined, structured process and to examine the interrater reliability of the ratings using the rating reference guide.

Methods

The development of the first version of the rating reference guide involved the following steps: (1) A trial of rating patients by several raters; (2) cognitive interviews with each rater to analyze the thought process involved in each rating; (3) the drafting of the rating reference guide by a multidisciplinary panel; and (4) a review by ICF specialists to confirm consistency with the ICF. Subsequently, we conducted a first field test to gain insight on the use of the guide in practice. The reference guide was modified based on the raters' feedback in the field test, and an interrater reliability test was conducted thereafter. Interrater agreement was evaluated using weighted kappa statistics with linear weights.

Results

The first version of the rating reference guide was successfully developed and field tested. The weighted kappa coefficient in the field testing ranged from 0.25 to 0.92 . The interrater reliability testing of the rating reference guide modified based on the field test results yielded an improved weighted kappa coefficient ranging from 0.54 to 0.85 .

\section{Conclusions}

In this study, we developed and modified a rating reference guide for the body function categories of the ICF Generic-30 Set. The interrater reliability test using the final version of the rating reference guide showed moderate to excellent interrater agreement, which encourages the use of the ICF in rehabilitation practice.

Trial registration

Not applicable.

\section{Background}

The International Classification of Functioning, Disability, and Health (ICF) is a framework for describing and organizing information on functioning and disability [1, 2]. Since the ICF was endorsed in May 2001, 
various initiatives have been undertaken to promote its implementation [3-8], including the development of ICF Core Sets based on a multi-modal international and interprofessional process. ICF Core Sets contain selected categories from the entire classification that can serve as minimum standards for assessing and documenting the functioning and health of individuals with a specific disease or disorder. In addition, two ICF sets have been developed for generic use. The ICF Generic Set (also called ICF Generic-7 Set) consists of seven ICF categories that are considered most relevant for assessing and documenting the functioning of the general population as well as different clinical populations irrespective of health condition, contexts, settings, and purposes [9]. The ICF Rehabilitation Set (also called ICF Generic-30 Set) is an extended version of the ICF Generic-7 Set comprising 30 ICF categories, and is used in the context of rehabilitation and disability to describe varying levels of functioning across various clinical populations and along the continuum of care [10]. [11]. Although ICF sets provide a specification of which domains to assess, they do not stipulate how to assess them.

In the ICF classification, the World Health Organization (WHO) proposed a rating system that consists of so-called "qualifiers" that can be used to code the severity of functioning problems. The qualifiers are as follows: $0=$ no problem; $1=$ mild problem; 2 =moderate problem; $3=$ severe problem; $4,=$ complete problem; $8=$ not specified; and $9=$ not applicable [1]. Unlike most existing clinical scales, there are no detailed or additional explanations for using qualifiers for rating functioning. The lack of more detailed guidance on how to use qualifiers may make rating of problems patients experience in a given ICF category more difficult, potentially leading to inconsistent ratings. For example, Uhlig et al. examined the interrater reliability of clinician ratings using ICF qualifiers and the ICF core set for rheumatoid arthritis, and reported low reliability [12]. In order to identify the potential for improving the interrater reliability of clinician ratings using ICF sets, Mukaino and colleagues conducted a multistage study using the activities and participation categories of the ICF Generic-30 Set [13]. Specifically, a rating guide for the activities and participation categories was developed and modified based on the results of a cognitive interview of clinicians who field tested the guide. The rating guide employed the 0-4 qualifier rating scale, as this had been shown to perform well in another study when used in the activities and participation component [14]. The interrater reliability using this modified version of the rating guide presented substantial to excellent interrater reliability. However, developing such a rating reference guide for body function categories may be more difficult. While problems in activities and participation can be rated relatively easy by indicating, for example, whether a person is able, conditionally able, or not able to perform a particular activity, as is done with existing clinical rating scales[15, 16], body function categories cannot be explained by a single factor (e.g. able to perform). Multiple factors must be considered in order to determine the magnitude of a body function problem. For example, the problems in category b280 Sensation of pain has several aspects, e.g. the extent of pain, pain frequency, or the site of pain. Thus, the rating could vary depending on which aspect the rater focuses on. One clinician may focus on the frequency of the pain, while another may focus on the maximum pain experienced by the patient. Furthermore, one may only ask patients about the intensity of the pain, while another may only consider the site of the pain. Thus, specifying what the category is addressing, for example in form of a 
guidance document with category specifications, can help clinicians to make an informed judgement for rating.

In this study, we aimed to create a rating reference guide for the nine body function categories of the ICF Generic-30 Set that leads to reliable ratings.

\section{Materials And Methods}

The development and assessment of the rating reference guide was conducted according to the flow chart shown in Figure 1.

\section{Development of the draft of the rating reference guide}

Prior to the development of the rating reference guide, the thought processes of clinicians when rating using qualifiers was assessed through a cognitive interview. First, a multi-disciplinary working group consisting of a physiatrist, a physical therapist, and an occupational therapist from the same hospital was organized to develop the initial draft of the reference guide. First, the working group members independently evaluated the functioning of the same nine patients (three acute patients, three subacute patients, and three chronic patients; age, $56.7 \pm 18.6$; seven males and two females; five with neurological diseases, three with orthopedic diseases, and one with respiratory disease) in the hospital, using the ICF Generic-30 Set and the original qualifier scoring[1]. The Japanese version of the simple, intuitive descriptions of the ICF Generic-30 Set [13] was used to facilitate the understanding of the category, which also supported the determination of the ratings. The Japanese-language simple, intuitive descriptions of the ICF Generic-30 Set was developed based on an established consensus process that has been promoted by national physical and rehabilitation medicine societies all over the world $[11,17,18]$. Cognitive interviews were conducted after the evaluation was completed, during which working group members who rated the patients were asked the following questions:

1. What did you consider when rating this category?

2. Why did you select this response option for this category (for example, why did you select qualifier 2 for the category "d450 walking")?

3. Why did you not select the adjacent response options (for example, why did you select qualifier 2 instead of 3)?

Subsequently, a qualitative content analysis of the cognitive interviews was conducted. The working group raters were asked to discuss the results of the interviews and develop a simple rating reference guide accordingly. The researcher who conducted the individual interviews moderated the discussion and guide development process. The working group raters were asked to develop the rating reference guide for a rating scale of 0 to 4 , to keep the guide as simple as possible, and to keep the response options of the scale consistent across the categories. The ICF qualifier response options "8: not specified" and "9: not applicable" were maintained in order to be consistent with the structure of the ICF qualifiers. The draft guide was then reviewed and modified by a multidisciplinary group of eight ICF experts with regard to 
consistency and simplicity. The resulting document was regarded as the first version of the rating reference guide for the body function categories of the ICF Generic-30 Set with a 0-4 rating scale (from now on referred to as "first version of the rating reference guide").

Field test of the guide in clinical practice

The field test using the first version of the rating reference guide was performed to obtain feedback on the use of the guide in real-life clinical practice. The guide was field tested by four independent raters (two physiatrists, one physical therapist, and one occupational therapist). Each patient involved in the field test was rated by two of the four raters.

After the raters completed patient evaluations using the rating reference guide, a researcher interviewed the four raters in order to determine what the raters found difficult in rating with the first version of the rating reference guide. The raters were asked following questions:

1. Did you have difficulty in rating with this guide?

2. If yes, what made it difficult for you to rate?

A qualitative analysis on the results of the interview was then conducted.

Modification of the reference guide

After the field test, a multidisciplinary panel, consisting of two physiatrists, two physical therapists, and two occupational therapists, was organized to modify the first version of the rating reference guide based on the feedback resulting from the field test. The panel was asked to discuss ideas to address the issues raised by the raters during the field test. The panel members considered the results of the interview of the four field test raters, as well as the record of the cognitive interview used to develop the initial draft , and the members discussed how to modify the guide to make it easier for clinicians to assign ratings.

\section{Study of interrater reliability among clinicians}

A second interrater reliability test was conducted with four raters (two physical therapists and two occupational therapists) who did not participate in the first interrater reliability study. Each patient was rated by two of the four raters.

The sample size required for a rigorous reliability study was determined by the number of response options (five), the minimum value for the desired kappa coefficient ( 0.3 for every ICF category), and the power $(90.0 \%)$ and alpha (0.05) we specified. As a result, the minimum sample size was calculated as 36 $[19,20]$. Accordingly, the minimum sample size for each rater was set at 36 patients, excluding the missing value. In total, 123 pairs were obtained for evaluation.

Data analysis 
Weighted kappa statistics were used to determine the interrater agreement among the raters in both interrater reliability studies. Weighted kappa statistics with linear weights[21] were calculated for each item of the body function categories of the ICF Generic-30 Set. Response options 8 ("not specified") and 9 ("not applicable") on the qualifier scale were not included in the kappa statistics and were considered as missing data. The standards for interpreting the kappa coefficients were as follows: $\leqq 0.20$, poor; $0.21-$ 0.40 , fair; $0.41-0.60$, moderate; $0.61-0.80$, substantial; and $\geqq 0.81$, excellent [22].

\section{Results}

Development of the first version of the rating reference guide

Table 1 shows the first version of the rating reference guide for body function categories of the ICF Generic-30 Set. In developing the rating reference guide, two key topics emerged from the qualitative content analysis of the discussion notes: What to rate in each category, and how to frame the response options. 


\begin{tabular}{|c|c|c|c|}
\hline \multirow[t]{2}{*}{ Table 1} & \multicolumn{3}{|c|}{$\begin{array}{l}\text { First version of the rating } \\
\text { reference guide }\end{array}$} \\
\hline & & $\begin{array}{l}\text { What aspect } \\
\text { should be } \\
\text { scored }\end{array}$ & What is the complete problem \\
\hline \multirow[t]{2}{*}{ b130 } & \multirow{2}{*}{$\begin{array}{l}\text { Energy } \\
\text { and drive } \\
\text { functions }\end{array}$} & $\begin{array}{l}\text { पThe extent of } \\
\text { the problem }\end{array}$ & \multirow[t]{2}{*}{ May include: Having no motivation or appetite at any time } \\
\hline & & $\begin{array}{l}\text { The } \\
\text { frequency of } \\
\text { the problem }\end{array}$ & \\
\hline \multirow[t]{2}{*}{ b134 } & \multirow[t]{2}{*}{$\begin{array}{l}\text { Sleep } \\
\text { functions }\end{array}$} & $\begin{array}{l}\text { पThe extent of } \\
\text { the problem }\end{array}$ & \multirow[t]{2}{*}{$\begin{array}{l}\text { May include: Incapable of sleep at all, or the sleeping } \\
\text { schedule has collapsed }\end{array}$} \\
\hline & & $\begin{array}{l}\text { पThe } \\
\text { frequency of } \\
\text { the problem }\end{array}$ & \\
\hline \multirow[t]{2}{*}{ b152 } & \multirow[t]{2}{*}{$\begin{array}{l}\text { Emotional } \\
\text { functions }\end{array}$} & $\begin{array}{l}\text { वThe extent of } \\
\text { the problem }\end{array}$ & \multirow[t]{2}{*}{$\begin{array}{l}\text { May include: Complete loss of control of emotions every } \\
\text { day, or incapable of expressing emotions }\end{array}$} \\
\hline & & $\begin{array}{l}\text { वThe } \\
\text { frequency of } \\
\text { the problem }\end{array}$ & \\
\hline \multirow[t]{2}{*}{ b280 } & \multirow[t]{2}{*}{$\begin{array}{l}\text { Sensation } \\
\text { of pain }\end{array}$} & $\begin{array}{l}\text { पThe extent of } \\
\text { the problem }\end{array}$ & \multirow[t]{2}{*}{$\begin{array}{l}\text { May include: Suffering from continuous intolerable pain } \\
\text { at any time }\end{array}$} \\
\hline & & $\begin{array}{l}\text { वThe } \\
\text { frequency of } \\
\text { the problem }\end{array}$ & \\
\hline \multirow[t]{2}{*}{ b455 } & \multirow{2}{*}{$\begin{array}{l}\text { Exercise } \\
\text { tolerance } \\
\text { functions }\end{array}$} & $\begin{array}{l}\text { पThe extent of } \\
\text { the problem }\end{array}$ & \multirow[t]{2}{*}{$\begin{array}{l}\text { May include: Incapable of bearing any single activity of } \\
\text { daily living at any time due to cardiorespiratory problems }\end{array}$} \\
\hline & & $\begin{array}{l}\text { पThe } \\
\text { frequency of } \\
\text { the problem }\end{array}$ & \\
\hline \multirow[t]{2}{*}{ b620 } & \multirow[t]{2}{*}{$\begin{array}{l}\text { Urination } \\
\text { functions }\end{array}$} & $\begin{array}{l}\text { पThe extent of } \\
\text { the problem }\end{array}$ & \multirow[t]{2}{*}{$\begin{array}{l}\text { May include: Complete urinary retention or continuous } \\
\text { incontinence at any time }\end{array}$} \\
\hline & & $\begin{array}{l}\text { पThe } \\
\text { frequency of } \\
\text { the problem }\end{array}$ & \\
\hline
\end{tabular}




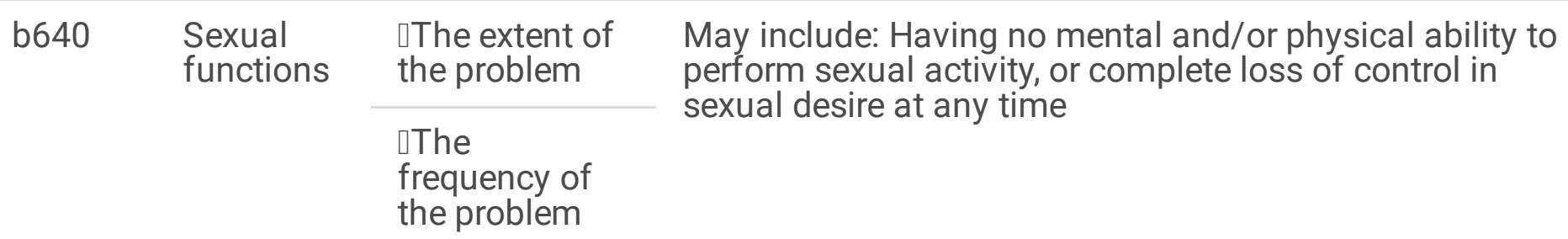

पThe

frequency of

the problem

\begin{tabular}{|c|c|c|c|}
\hline \multirow[t]{2}{*}{ b710 } & \multirow{2}{*}{$\begin{array}{l}\text { Mobility } \\
\text { of joint } \\
\text { functions }\end{array}$} & $\begin{array}{l}\text { पThe extent of } \\
\text { the problem }\end{array}$ & \multirow[t]{2}{*}{ May include: Complete joint contracture in all major joints } \\
\hline & & $\begin{array}{l}\text { वThe ratio of } \\
\text { the joint with } \\
\text { the problem }\end{array}$ & \\
\hline \multirow[t]{2}{*}{ b730 } & \multirow{2}{*}{$\begin{array}{l}\text { Muscle } \\
\text { power } \\
\text { functions }\end{array}$} & $\begin{array}{l}\text { पThe extent of } \\
\text { the problem }\end{array}$ & \multirow[t]{2}{*}{$\begin{array}{l}\text { May include: Complete loss of muscle power in all major } \\
\text { muscles }\end{array}$} \\
\hline & & $\begin{array}{l}\text { पThe ratio of } \\
\text { the joint with } \\
\text { the problem }\end{array}$ & \\
\hline
\end{tabular}

Ratings *Note that the rating should reflect the body function without the help of devices

$0 \quad$ No

problem

$1 \quad$ Mild

problem

2 Moderate

problem

\begin{tabular}{|ll}
3 & $\begin{array}{l}\text { Severe } \\
\text { problem }\end{array}$ \\
\hline 4 & $\begin{array}{l}\text { Complete } \\
\text { problem }\end{array}$ \\
\hline 8 & $\begin{array}{l}\text { Not } \\
\text { specified }\end{array}$ \\
\hline 9 & $\begin{array}{l}\text { Not } \\
\text { applicable }\end{array}$ \\
\hline
\end{tabular}

What to rate in each category.

The challenges posed by having several aspects (e.g. severity, frequency, location) to consider in rating a given category were discussed. For example, for the category "b134 sleep functions" the problem could 
be understood as a combination of the frequency and the extent of problems in sleep functions. To address these challenges, working group members highlighted specific aspects to focus on when evaluating each category. The overall sentiment was that having too many aspects to focus on would complicate the rating process and that the rating reference guide should be kept as simple as possible. Accordingly, the working group members identified two main aspects that should be considered when rating the body function categories of the ICF Generic-30 Set - the extent and frequency of the problem in the given category.

\section{How to frame the response options}

The working group members also proposed that concrete examples should be provided to improve the clarity of the guide, and that these examples should include information on clinical instruments that are commonly used to assess the given category. This idea was first adopted during the development of the initial draft; however, during the review process by ICF experts, there was a concern raised that this approach may result in overly complicated manuals. Since every category would highlight several aspects that should be considered during rating, the manuals would have to include specific descriptions of those aspects as well as define how to consider a combination of problems. For example, if we rate the status of muscle functions with manual muscle testing, then we should also consider how many and which muscles are impaired. Several reviewers raised concerns that this would make the use of the rating reference guide in the clinic too complicated. Accordingly, concrete descriptions based on the clinical instruments in the reference guide were removed from the initial draft.

The first version of the rating reference guide was simplified as follows: Two major aspects were specified and should be considered when assigning ratings (see Table 1) for each category . For example, for "d620 urination function," the guide instructs raters to consider the frequency and extent of the problem when rating this category from 0 to 4 . No further explanation regarding each response option was added.

Field test to gain feedback on the rating reference guide in practical use

A total of 60 individuals (52 inpatients and 8 community-dwelling elderly) participated in this study. The 52 patients underwent rehabilitation during April 2017 to November 2018 at Fujita Health University Hospital and Fujita Health University Nanakuri Memorial Hospital. Among these 60 individuals (38 males and 22 females), 31 had neurological disease; 9 had musculoskeletal disease; 9 had cardiopulmonary disease; and 4 had other health issues. The mean age of the patients was $64.5 \pm 17.7$ years.

The results of the interrater reliability calculation of the ratings using the initial version of the rating reference guide is shown in Table 2. The weighted kappa statistics ranged from 0.25 to 0.92 , indicating low interrater reliability for several categories, while moderate to excellent for other categories. For example, the weighted kappa coefficients for b620 Urination functions indicated an excellent interrater reliability, while the kappa for "b152 emotional functions" a low or fair interrater reliability [22]. 


\begin{tabular}{|lll|}
\hline Table 2 & Interrater reliability of the rating using the first version of the rating reference guide \\
\hline & Categories & Weighted $\mathrm{K}$ \\
\hline b130 & Energy and drive functions & 0.56 \\
\hline b134 & Sleep functions & 0.62 \\
\hline b152 & Emotional functions & 0.25 \\
\hline b280 & Sensation of pain & 0.44 \\
\hline b455 & Exercise tolerance functions & 0.55 \\
\hline b620 & Urination functions & 0.92 \\
\hline b640 & Sexual functions & 0.80 \\
\hline b710 & Mobility of joint functions & 0.58 \\
\hline b730 & Muscle power functions & 0.65 \\
\hline & & \\
\hline
\end{tabular}

Investigation of the potential problems with the first version of the rating reference guide

According to the results of the first field test, the guidance information for the following four categories with the lowest interrater reliability were identified needing improvement: "b130 energy and drive functions," "b152 emotional functions", "b280 sensation of pain," and "b455 exercise tolerance functions". The following problems raised during the field test were discussed in an effort to improve the interrater reliability of these categories: Difficulty distinguishing between mild problems and moderate problems, difficulty rating patients who cannot express their emotions ("b152 emotional functions"), and lack of consideration of the number of pain sites ("b280 sensation of pain").

Two of the raters indicated that it was difficult to distinguish mild problems from moderate problems. The ICF published by the World Health Organization states that a moderate problem is "generally up to half of the scale of the total problem" [1]; thus, the raters felt that differences between moderate and severe problems were relatively easy to distinguish. However, other than this clarifying statement about the interpretation of a moderate problem, there are no clarifications about mild problems, only the presentation of the corresponding percentages of mild problems and moderate problems $(5 \%-24 \%$ and $25 \%-49 \%$, respectively). This makes it difficult to differentiate between mild and moderate problems. This lack of guidance was seen as problematic for rating patients in the clinic.

The second point raised by the raters was the complexity of the first version of the rating reference guide. The first version of the rating reference guide outlined specifically for each category various aspects to be rated and an example of what a complete problem would encompass. The raters were required to take 
this information into account when rating each category, but without a concrete guide for each response option (0 to 4 ). Several raters stated that these rating instructions were confusing and made the rating difficult.

An issue related to "b152 emotional functions" was also raised. Specifically, a rater highlighted the difficulty in evaluating the emotional functions of patients with problems expressing emotions. The first version of the guide indicated that a "complete problem" in b152 is exemplified by completely losing control of emotions every day. However, there are patients who do not lose control of emotions but rather are unable to express emotions. Three of the raters agreed that the inability to express emotions should also be recognized as a problem in b152.

With regard to rating "b280 sensation of pain" the first version of the rating reference guide instructed that frequency and the extent of pain should be considered when rating. However, two of the raters indicated that the number of pain sites also has an influence on the degree of the problem.

\section{Modification of the reference guide}

The reference guide was modified by a multidisciplinary panel according to the feedback from the raters in the field test. As the feedback from the raters were focused on the issues in the rating and did not always include concrete suggestion for improvement, the investigators decided to revisit the records of the first cognitive interviews that resulted in the initial draft of the guide (see figure 1). This helped to address the difficulty in distinguishing mild problems from moderate problems. According to the interview records, several raters mentioned that assigning a rating of 1 (mild problem) for five of the nine categories ("b130 energy and drive functions," "b134 sleep functions," "b280 sensation of pain," "b710 mobility of joint functions," and "b730 muscle power functions") was due to the lack of impact these body functions had on daily activities. Given this, the members of the panel added text to the guide that describes a mild problem in a particular ICF category as a problem that does not affect daily activities. To clarify the difference between a rating of 2 (moderate problem) and a rating of 3 (severe problem), the following explanations were given: A rating of 2 "may include a problem that exceeds a rating of 1 , but still remains a relatively minor problem $(<50 \%)$ in the given category", and a rating of 3 "may include a problem that is a major problem ( $\geqq 50 \%)$ in the given category". The percentages $(<50 \%$ and $\geqq 50 \%)$ were added to emphasize that a "moderate problem" is "generally up to half of the scale of the total problem" [1]; this further distinguishes the ratings 2 and 3. The percentage was set to describe how much is the problem is relative to a complete problem ( $100 \%$ as the amount of the problem). For example, in scoring "b130 energy and drive functions", a complete problem is described as "having no motivation nor appetite at any time", and this is regarded to be $100 \%$ of the problem. Raters then consider the amount of problem a person has in b130 by considering the extent and the frequency of the lack of motivation or appetite.

The rating reference guide descriptions for "b152 emotional functions" and "b280 sensation of pain" were also modified. For "b152 emotional functions," the following explanation describing a complete problem in this category was added: "being incapable of expressing emotions at any time". For "b280 sensation of 
pain," the pain site was added as an aspect to be considered prior to assigning a rating score. The modified rating reference guide (from now on referred to as "final version of the rating reference guide") is shown in Table 3. 
Table 3 Second version of the rating reference guide

Category Aspect to be scored Description of each response option

* The percentage describes the severity of the problem, if $100 \%$ means it is a complete problem. **The rating should reflect the body's function without the help of devices.

b130 Energy Extent and frequency of the and drive functions problem, such as loss of

motivation or appetite

\section{0: No problem}

1: Mild problem: May include problems with energy and drive functions that do not affect the patient's daily activities

2: Moderate problem: May include a problem in energy and drive functions that exceeds 1 , but remains a relatively minor problem $(<50 \%)$

3: Severe problem: May include a major problem $(\geqq 50 \%)$ in energy and drive functions

4: Complete problem: May include a complete problem with energy and drive functions, such as having no motivation or appetite at any time b134 Sleep Extent and frequency of the functions problem, such as shortage of sleep or irregular sleep schedules

\section{0: No problem}

1: Mild problem: May include problems with sleep that do not affect the patient's daily activities

2: Moderate problem: May include a problem with sleep that exceeds 1 , but remains a relatively minor problem $(<50 \%)$

3: Severe problem: May include a major problem ( $\geqq 50 \%)$ with sleep

Complete problem: May include a complete problem with sleep, such as being incapable of sleeping, or a complete day-night reversal every day

\section{b152 Emotional} functions
Extent and frequency of the problem, such as loss of emotional control or lack of emotional expression

\section{$0:$ No problem}

1: Mild problem: May include problems with emotions that do not affect the patient's daily activities

2: Moderate problem: May include problems with emotions that exceed 1 , but remains 
relatively minor $(<50 \%)$

3: Severe problem: May include a major problem ( $\geqq 50 \%)$ with emotions

4: Complete problem: May include a complete problem with emotions, such as complete loss of control of emotions, or being incapable of expressing emotions at any time

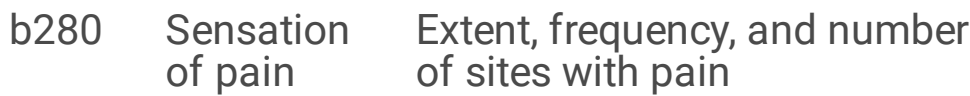

\section{0 : No problem}

1: Mild problem: May include problems with sensations of pain, but does not affect the patient's daily activities

2: Moderate problem: May include a problem with sensations of pain that exceeds 1 , but remains a relatively minor problem $(<50 \%)$

3: Severe problem: May include a major problem ( $\geqq 50 \%)$ with sensations of pain

4: Complete problem: May include a complete problem with sensations of pain, such as continuous, intolerable pain b455 Exercise tolerance functions
Extent and frequency of the problem, such as decline in respiratory and cardiovascular capacity that is required to perform daily activities

\section{0 : No problem}

1: Mild problem: May include problems with exercise tolerance that do not affect the patient's daily activities

2: Moderate problem: May include a problem with exercise tolerance that exceeds Level 1 , but remains a relatively minor problem $(<50 \%)$

3: Severe problem: May include a major problem ( $\geqq 50 \%$ ) with exercise tolerance

4: Complete problem: May include a complete problem with exercise tolerance, such as being incapable of bearing any single activity of daily living at any time due to cardiorespiratory problems 


\begin{tabular}{|c|c|c|c|}
\hline \multirow[t]{5}{*}{ b620 } & \multirow{5}{*}{$\begin{array}{l}\text { Urination } \\
\text { functions }\end{array}$} & \multirow{5}{*}{$\begin{array}{l}\text { Extent and frequency of the } \\
\text { problem, such as difficulty } \\
\text { urinating or urinary } \\
\text { incontinence }\end{array}$} & 0: No problem \\
\hline & & & $\begin{array}{l}\text { 1: Mild problem: May include problems with } \\
\text { urination that do not affect the patient's daily } \\
\text { activities }\end{array}$ \\
\hline & & & $\begin{array}{l}\text { 2: Moderate problem: May include a problem } \\
\text { with urination that exceeds } 1 \text {, but remains a } \\
\text { relatively minor problem }(<50 \%)\end{array}$ \\
\hline & & & $\begin{array}{l}\text { 3: Severe problem: May include a major } \\
\text { problem ( } \geqq 50 \%) \text { with urination }\end{array}$ \\
\hline & & & $\begin{array}{l}\text { 4: Complete problem: May include a } \\
\text { complete problem with urination, such as } \\
\text { complete urinary retention or continuous } \\
\text { incontinence at any time }\end{array}$ \\
\hline \multirow[t]{5}{*}{ b640 } & \multirow{5}{*}{$\begin{array}{l}\text { Sexual } \\
\text { functions }\end{array}$} & \multirow{5}{*}{$\begin{array}{l}\text { Extent and frequency of the } \\
\text { problem, such as loss of sexual } \\
\text { desire and/or physical ability to } \\
\text { engage in sexual activity }\end{array}$} & 0: No problem \\
\hline & & & $\begin{array}{l}\text { 1: Mild problem: May include problems with } \\
\text { sexual functions that do not affect the } \\
\text { patient's daily activities }\end{array}$ \\
\hline & & & $\begin{array}{l}\text { 2: Moderate problem: May include a problem } \\
\text { with sexual functions that exceeds } 1 \text {, but } \\
\text { remains a relatively minor problem }(<50 \%)\end{array}$ \\
\hline & & & $\begin{array}{l}\text { 3: Severe problem: May include a major } \\
\text { problem ( } \geqq 50 \%) \text { with sexual functions }\end{array}$ \\
\hline & & & $\begin{array}{l}\text { 4: Complete problem: May include a } \\
\text { complete problem with sexual functions, } \\
\text { such as a complete loss of sexual desire } \\
\text { and/or physical ability to engage in sexual } \\
\text { activity at any time }\end{array}$ \\
\hline \multirow[t]{5}{*}{ b710 } & \multirow{5}{*}{$\begin{array}{l}\text { Mobility } \\
\text { of joint } \\
\text { functions }\end{array}$} & \multirow{5}{*}{$\begin{array}{l}\text { Extent of the problem, such as } \\
\text { joint contracture, or limitations } \\
\text { in range of motion and } \\
\text { percentage of joints with } \\
\text { mobility problems }\end{array}$} & 0: No problem \\
\hline & & & $\begin{array}{l}\text { 1: Mild problem: May include problems with } \\
\text { joint mobility functions that do not affect the } \\
\text { patient's daily activities }\end{array}$ \\
\hline & & & $\begin{array}{l}\text { 2: Moderate problem: May include problems } \\
\text { with joint mobility that exceed } 1 \text {, but remains } \\
\text { a relatively minor problem }(<50 \%)\end{array}$ \\
\hline & & & $\begin{array}{l}\text { 3: Severe problem: May include a major } \\
\text { problem ( } \geqq 50 \%) \text { with joint mobility }\end{array}$ \\
\hline & & & $\begin{array}{l}\text { 4: Complete problem: May include a } \\
\text { complete problem with joint mobility, such as } \\
\text { complete joint contracture in all of the major } \\
\text { joints }\end{array}$ \\
\hline
\end{tabular}




\begin{tabular}{|c|c|c|}
\hline b730 & $\begin{array}{l}\text { Muscle } \\
\text { power }\end{array}$ & $\begin{array}{l}\text { Extent of the problem, and } \\
\text { percentage of ioints with }\end{array}$ \\
\hline & functions & muscle power problems \\
\hline
\end{tabular}

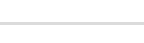

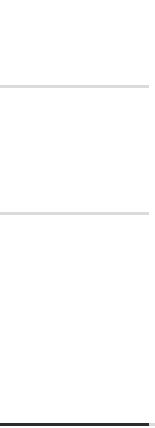

Interrater reliability using the final version of the rating reference guide

A total of 123 patients who underwent rehabilitation from April to June 2020 at Fujita Health University Hospital participated in this study. Among these individuals (78 males and 45 females), 93 had neurological disease; 17 had musculoskeletal disease; 9 had cardiopulmonary disease; and 4 had various other health issues. The mean age of the patients was $69.1 \pm 15.1$ years. The results of the interrater reliability study by four raters (two physical therapists and two occupational therapists) using the final version of the rating reference guide are shown in Table 4 . The weighted kappa coefficient ranged from 0.54 to 0.85 , indicating that all of the categories had moderate to excellent interrater reliability. A high rate of missing data (41.5\%) was observed for "b640 sexual functions". 
Table 4 Interrater reliability of the rating using the second version of the rating reference guide

\begin{tabular}{|llll|}
\hline & Categories & Weighted $\mathrm{k}$ & Missing values \\
\hline b130 & Energy and drive functions & 0.80 & 0 \\
\hline b134 & Sleep functions & 0.69 & 0 \\
\hline b152 & Emotional functions & 0.69 & 0 \\
\hline b280 & Sensation of pain & 0.82 & $1(0.8 \%)$ \\
\hline b455 & Exercise tolerance functions & 0.67 & 0 \\
\hline b620 & Urination functions & 0.79 & $2(1.6 \%)$ \\
\hline b640 & Sexual functions & 0.54 & $51(41.5 \%)$ \\
\hline b710 & Mobility of joint functions & 0.77 & 0 \\
\hline b730 & Muscle power functions & 0.85 & 0 \\
\hline
\end{tabular}

\section{Discussion}

In the current study, a rating reference guide for the nine body function categories of the ICF Generic-30 Set was developed using a predefined process that involved clinicians' ratings, cognitive interviews, a field test and reviews by multidisciplinary panels, and interrater reliability studies on the first field-tested version and final (post-field test) version of the guide. The first version of the guide outlined which aspects to rate, gave an example of what should be considered a complete problem, and provided a rating scale of $0-4$ without descriptions of the response options. The interrater reliability of the first version revealed low agreement of the ratings among clinicians in several categories. The guide was subsequently modified to produce a final version that was again tested for interrater reliability. The results of this second interrater reliability study showed moderate to excellent interrater reliability for all categories, indicating an improvement of the guide - from the standpoint of interrater reliability.

Several challenges arose in developing the rating reference guide, one of which was deciding which aspects of the body function problem to focus on when rating. The first version of the rating reference guide addressed this problem by defining frequency and extent of the problem as the aspects to focus on. Defining the specific aspects to focus on had a positive effect on the reliability of the rating. Indeed, the overall weighted kappa values for the categories were higher in the current study than those in previous studies [12, 23]. However, for several items, the weighted kappa coefficients showed lower reliability compared to the good to excellent interrater reliability of the body function-related items in the clinical scales used in previous studies[24-26]. Moreover, a common point raised by the raters who participated in the first interrater reliability study was the difficulty in deciding between the rating 1 (mild problem) and rating 2 (moderate problem), apparently due to the lack of a clear explanation on the 
differences between them. Difficulty in rating functioning using ICF qualifiers as reflected in the interrater reliability was addressed in a previous study. Uhlig and colleagues showed that low interrater reliability of ICF qualifier-based ratings could be improved by collapsing the response options, combining rating 1 and 2 into a single response option. [12] We used a different approach to address this problem - we added explanations to frame the response options based on the feedback the raters gave during the field test and the review of the notes from the cognitive interviews. The effect on daily activities was mentioned as the difference between rating 1 and rating 2; this may prove controversial, since it is important to assess the ICF components of body functions and activities and participation separately. According to the ICF[1], ICF categories and domains are mutually exclusive. More importantly, rating the ICF components independently facilitates the examination of their subsequent relationship. Nevertheless, the impact of body function impairments on daily activities is an important aspect in assessing the overall functioning of patients, and the extent to which the impairment of body functions affects other aspects of functioning is still the focus of rating respective body functions. This reflects the interrelationship between body functions, activities and participation, and contextual factors as shown in the biopsychosocial model of the ICF [1].

The modifications to the rating reference guide also included changes related to "b152 emotional functions". In the first version of the guide, b152 only focused on losing control of emotions. However, in rehabilitation clinics, the lack of emotional expression is another type of problem in emotional functions that is frequently observed. The lack of emotional expression is a functioning manifestation of depression that is common in many rehabilitation patients [27, 28]. Given this, the modification of the rating reference guide to include lack of emotional expression is considered justified.

Also revised was the guidance on evaluating "b280 sensation of pain", i.e. adding the number of pain sites as a factor to be considered in the rating based on the interview with the raters in the field test. Previous studies show that the number of pain sites is a potential modifier of pain severity and affects the health-related quality of life of patients $[29,30]$.

After the aforementioned modifications were implemented, the final rating reference guide underwent a second interrater reliability test. The results showed that the weighted kappa coefficient of eight out of nine categories were higher than 0.60 , indicating substantial to excellent reliability for these items. The high interrater reliability of the eight categories is comparable to the results of other widely used clinical scales [24-26], and supports the feasibility of the use of body function categories of the ICF Generic-30 Set in real clinics using the final version of the rating reference guide. The only category that did not show a high reliability was"b640 sexual functions"; it demonstrated moderate reliability. In addition, with $41.5 \%$ the rate of missing data in b640 was high. This high rate of missing data may have been due to the considerable number of elderly participants for whom sexual functions may have been less relevant or possibly also due to the decision by rating clinicians to avoid asking patients about sexual issues. A study of younger patients with higher requirements in sexual function may contribute to further refinement of the reference guide for "b640 sexual functions". 
There have been international efforts to develop ICF-based clinical tools. Groundwork to develop such tools include the development of ICF sets and corresponding simple and intuitive descriptions of the ICF categories contained in such sets $[3,10,11,17,18]$. In addition, studies on using such ICF sets with simple descriptions have also been conducted [31-33]. The majority of these studies used an intuitive rating scale, whereby "intuitive" means that there is no specific rating guide provided. For example, a project in China with a large sample has used the ICF Generic-7 Set with an intuitive rating scale of 0 to $10[32,34]$. The advantage of an intuitive rating system is that it does not require a complicated process to define each response option. Although we were aware of this approach, we chose to develop the rating reference guide route and specifically to develop a scale system with descriptions of each response option. For one, this approach is similar to that in most clinical scales, and although developing response option descriptions is resource-intensive, this approach has a clear advantage in that clinicians can better understand what each rating in each category means. Clinicians need to understand what they are rating in order to accurately rate/measure patient functioning. This is especially true considering the feedback from the clinicians in the present study - that it would be better to focus on specific aspects, e.g. frequency, extent of problem, influence on daily activity, when rating body function categories. Creating a standard rating guide would not only make rating for clinicians easier, it would help to ensure reliable measurement of patient functioning. Thus, the development of a rating reference guide for ICF categories is useful for clinicians who use ICF in clinical practice, and may facilitate system-wide implementation of the ICF in clinical settings.

\section{Limitations}

In this study, the raters were experienced rehabilitation experts. Since previous studies have shown that clinical experience could influence interrater reliability $[35,36]$, the reliability may be lower with less experienced experts. Further investigations are necessary to determine whether interrater reliability can be achieved with less experienced rehabilitation experts or other medical experts, such as nurses, who are less familiar with functional evaluation. If the interrater reliability is affected by the experience in functional evaluation, development of an education system for the raters and investigation into its effectiveness would be warranted. Another shortcoming of the current study was the characteristics of the patients who participated, i.e. a considerable number of the participants were elderly, predominately $(89.4 \%)$ patients with stroke and orthopedic disease. Nevertheless, since patients with neurological and orthopedic disease make up the majority of rehabilitation patients, the present results at least support the potential use of the rating reference guide in rating rehabilitation patients. Further investigation with a more diverse sample would underscore the generalizability of the findings.

\section{Conclusion}

A rating reference guide for body function categories of the ICF Generic-30 Set was successfully developed, and sufficient levels of interrater reliability were achieved after modifications. This guide is expected to support clinicians in the use of the ICF in rehabilitation clinical practice. 


\section{Abbreviations}

ICF: International Classification of Functioning, Disability, and Health; WHO: World Health Organization

\section{Declarations}

This study was approved by the Research Ethics Board of Fujita Health University (HM18-020). All participants provided written informed consent. All methods were carried out in accordance with relevant guidelines and regulations.

\section{Consent for publication}

Not applicable

\section{Availability of data and material:}

The datasets used and/or analysed during the current study are available from the corresponding author on reasonable request.

\section{Competing interests}

The authors declare no conflict of interest in conducting this research.

\section{Funding}

This research was supported by the Grants for Research on Health and Welfare for the research project titled "The establishment of a mechanism for evaluation and information sharing using the International Classification of Functioning, Disability and Health to integrate medical and long-term care services" (H30-statistics-general-003: Principal Investigator: Masahiko Mukaino).

\section{Authors' contributions}

YS, MM, BP and GS conceptualized and designed the study. YS, MM, BP, SY, SI, SS, YO and KM conducted the development of rating reference guide. YS and MM recruited the participants, collected the data, and performed the software analysis in interrater reliability study. YS, MM, BP, SY, SI, SS, MS, YO and GS interpreted results from the data. YS, MM, BP, MS, YO, ES and GS drafted the original manuscript and finalized the manuscript. ES,YO and GS supervised the whole process of study. All authors have read and approved the final version of the manuscript.

\section{Acknowledgements}

The authors would like to express special thanks to Emiko Oikawa, who supported the whole process of this study with her expertise in the ICF. 


\section{References}

1. WHO: International classification of Functioning, Disability and Health, 1st edn. Geneva; 2001.

2. Stucki G, Prodinger B, Bickenbach J: Four steps to follow when documenting functioning with the International Classification of Functioning, Disability and Health. Eur J Phys Rehabil Med 2017, 53(1):144-149.

3. Selb M, Escorpizo R, Kostanjsek N, Stucki G, Ustun B, Cieza A: A guide on how to develop an International Classification of Functioning, Disability and Health Core Set. Eur J Phys Rehabil Med 2015, 51(1):105-117.

4. Ewert T, Grill E, Bartholomeyczik S, Finger M, Mokrusch T, Kostanjsek N, Stucki G: ICF Core Set for patients with neurological conditions in the acute hospital. Disabil Rehabil 2005, 27(7-8):367-373.

5. Grill E, Ewert T, Chatterji S, Kostanjsek N, Stucki G: ICF Core Sets development for the acute hospital and early post-acute rehabilitation facilities. Disabil Rehabil 2005, 27(7-8):361-366.

6. Grill E, Hermes R, Swoboda W, Uzarewicz C, Kostanjsek N, Stucki G: ICF Core Set for geriatric patients in early post-acute rehabilitation facilities. Disabil Rehabil 2005, 27(7-8):411-417.

7. Wildner M, Quittan M, Portenier L, Wilke S, Boldt C, Stucki G, Kostanjsek N, Grill E: ICF Core Set for patients with cardiopulmonary conditions in early post-acute rehabilitation facilities. Disabil Rehabil 2005, 27(7-8):397-404.

8. Boldt C, Grill E, Wildner M, Portenier L, Wilke S, Stucki G, Kostanjsek N, Quittan M: ICF Core Set for patients with cardiopulmonary conditions in the acute hospital. Disabil Rehabil 2005, 27(7-8):375380.

9. Cieza A, Oberhauser C, Bickenbach J, Chatterji S, Stucki G: Towards a minimal generic set of domains of functioning and health. BMC Public Health 2014, 14:218.

10. Prodinger B, Cieza A, Oberhauser C, Bickenbach J, Ustun TB, Chatterji S, Stucki G: Toward the International Classification of Functioning, Disability and Health (ICF) Rehabilitation Set: A Minimal Generic Set of Domains for Rehabilitation as a Health Strategy. Arch Phys Med Rehabil 2016, 97(6):875-884.

11. Gimigliano F, Selb M, Mukaino M, Baffone C, Bickenbach J, Patrick JE, Gutenbrunner C, Li J, Negrini S, Stucki G: Strengthening rehabilitation in health systems worldwide by implementing information on functioning in rehabilitation practice, quality management, and policy: 2018 status report. The Journal of the International Society of Physical and Rehabilitation Medicine 2018, 1(2):37.

12. Uhlig T, Lillemo S, Moe RH, Stamm T, Cieza A, Boonen A, Mowinckel P, Kvien TK, Stucki G: Reliability of the ICF Core Set for rheumatoid arthritis. Ann Rheum Dis 2007, 66(8):1078-1084.

13. Mukaino M, Prodinger B, Yamada S, Senju Y, Izumi SI, Sonoda S, Selb M, Saitoh E, Stucki G: Supporting the clinical use of the ICF in Japan - development of the Japanese version of the simple, intuitive descriptions for the ICF Generic-30 set, its operationalization through a rating reference guide, and interrater reliability study. BMC Health Serv Res 2020, 20(1):66. 
14. Prodinger B, Stucki G, Coenen $M$, Tennant A: The measurement of functioning using the International Classification of Functioning, Disability and Health: comparing qualifier ratings with existing health status instruments. Disabil Rehabil 2019, 41(5):541-548.

15. Keith RA, Granger CV, Hamilton BB, Sherwin FS: The functional independence measure: a new tool for rehabilitation. Adv Clin Rehabil 1987, 1:6-18.

16. Mahoney FI, Barthel DW: Functional evaluation: The barthel index. Md State Med J 1965, 14:61-65.

17. Prodinger B, Reinhardt JD, Selb M, Stucki G, Yan T, Zhang X, Li J: Towards system-wide implementation of the International Classification of Functioning, Disability and Health (ICF) in routine practice: Developing simple, intuitive descriptions of ICF categories in the ICF Generic and Rehabilitation Set. J Rehabil Med 2016, 48(6):508-514.

18. Selb M, Gimigliano F, Prodinger B, Stucki G, Pestelli G, locco M, Boldrini P: Toward an International Classification of Functioning, Disability and Health clinical data collection tool: the Italian experience of developing simple, intuitive descriptions of the Rehabilitation Set categories. Eur J Phys Rehabil Med 2017, 53(2):290-298.

19. Flack VF, Afifi A, Lachenbruch P, Schouten H: Sample size determinations for the two rater kappa statistic. J Psychometrika 1988, 53(3):321-325.

20. Bujang MA, Baharum N: Guidelines of the minimum sample size requirements for Kappa agreement test. J Epidemiology, Biostatistics and Public Health 2017, 14(2).

21. Cicchetti DV, Allison T: A new procedure for assessing reliability of scoring EEG sleep recordings. American Journal of EEG Technology 1971, 11(3):101-110.

22. Landis JR, Koch GG: The measurement of observer agreement for categorical data. Biometrics 1977, 33(1):159-174.

23. Hilfiker R, Obrist S, Christen G, Lorenz T, Cieza A: The use of the comprehensive International Classification of Functioning, Disability and Health Core Set for low back pain in clinical practice: a reliability study. Physiother Res Int 2009, 14(3):147-166.

24. Ottenbacher KJ, Hsu Y, Granger CV, Fiedler RC: The reliability of the functional independence measure: a quantitative review. Arch Phys Med Rehabil 1996, 77(12):1226-1232.

25. Telenius EW, Engedal K, Bergland A: Inter-rater reliability of the Berg Balance Scale, 30 s chair stand test and $6 \mathrm{~m}$ walking test, and construct validity of the Berg Balance Scale in nursing home residents with mild-to-moderate dementia. BMJ Open 2015, 5(9):e008321.

26. Savic G, Bergström EM, Frankel HL, Jamous MA, Jones PW: Inter-rater reliability of motor and sensory examinations performed according to American Spinal Injury Association standards. Spinal Cord 2007, 45(6):444-451.

27. Robinson RG, Jorge RE: Post-Stroke Depression: A Review. Am J Psychiatry 2016, 173(3):221-231.

28. Lim SW, Shiue YL, Ho CH, Yu SC, Kao PH, Wang JJ, Kuo JR: Anxiety and Depression in Patients with Traumatic Spinal Cord Injury: A Nationwide Population-Based Cohort Study. PLoS One 2017, 12(1):e0169623. 
29. Lacey RJ, Belcher J, Rathod T, Wilkie R, Thomas E, McBeth J: Pain at multiple body sites and healthrelated quality of life in older adults: results from the North Staffordshire Osteoarthritis Project. Rheumatology (Oxford) 2014, 53(11):2071-2079.

30. Dragioti E, Larsson B, Bernfort L, Levin LA, Gerdle B: A cross-sectional study of factors associated with the number of anatomical pain sites in an actual elderly general population: results from the PainS65+ cohort. J Pain Res 2017, 10:2009-2019.

31. Gimigliano F, De Sire A, Gastaldo M, Maghini I, Paoletta M, Pasquini A, Boldrini P, Selb M, Prodinger B: Use of the International Classification of Functioning, Disability and Health Generic-30 Set for the characterization of outpatients: Italian Society of Physical and Rehabilitative Medicine Residents Section Project. Eur J Phys Rehabil Med 2019, 55(2):258-264.

32. Liu S, Reinhardt JD, Zhang X, Ehrmann C, Cai W, Prodinger B, Liu S, Li J: System-wide Clinical Assessment of Functioning Based on the International Classification of Functioning, Disability and Health in China: Interrater Reliability, Convergent, Known Group, and Predictive Validity of the ICF Generic-6. Arch Phys Med Rehabil 2018, 100(8):1450-1457.

33. Frontera W, Gimigliano F, Melvin J, Li J, Li L, Lains J, Stucki G: ClinFIT: ISPRM's Universal Functioning Information Tool based on the WHO's ICF. The Journal of the International Society of Physical and Rehabilitation Medicine 2019, 2(1):19.

34. Ehrmann C, Prodinger B, Stucki G, Cai W, Zhang X, Liu S, Liu S, Li J, Reinhardt JD: ICF Generic Set as new standard for the system wide assessment of functioning in China: a multicentre prospective study on metric properties and responsiveness applying item response theory. BMJ Open 2018, 8(12): $\mathrm{e} 021696$.

35. Carr EK, Kenney FD, Wilson-Barnett J, Newham DJ: Inter-rater reliability of postural observation after stroke. Clin Rehabil 1999, 13(3):229-242.

36. Brunnekreef JJ, van Uden CJ, van Moorsel S, Kooloos JG: Reliability of videotaped observational gait analysis in patients with orthopedic impairments. BMC Musculoskelet Disord 2005, 6:17.

\section{Figures}


Developm ent In itial Draft - Multidisciplinary working group

Three rehabilitation experts rated the same nine patients using simple, intuitive descriptions

$\downarrow$

Developm ent In itial Draft - Cognitive interviews with the working group raters

[1] What did you consider when rating this category?

[2] Why did you select this response option for this category?

[3] Why didn't you select the adjacent response options? $\downarrow$

Developm ent In itial Draft - Discussion cognitive review results and develop initial draft

The working group raters and the interviewer discussed the findings of the qualitative analysis of cognitive interviews and the raters developed the initial draft of the rating reference guide

$\stackrel{\text { INITIAL DRAFT OF RATING REFERENCE GUIDE }}{\downarrow}$

Developm ent of the First Version of the Guide - Review by ICF experts and subsequent modification Critical appraisal and modification in terms of consistency with the ICF as such and its categories

$\underset{\substack{\text { FIRST VERSION OF RATING REFERENCE GUIDE } \\ \downarrow}}{ }$

Field test of rating refer ence guide - First interrater reliability study and interview of the raters Interrater reliability study and interviews with the aim to gain feedback from raters based on practical use of the guide

$\checkmark$ Field test of rating reference guide - Revision of guide based on field test results

Revision of the rating reference guide by a multidisciplinary panel according to the feedback from the first interrater reliability study

$\downarrow$

Field test of rating reference guide - Second interrater reliability study

Interrater reliability study with the revised rating reference guide

FINAL VERSION OF RATING REFERENCE GUIDE

Figure 1

Flow diagram for the development process of the rating reference guide 